\title{
Blood Chemistry of Wild Brazilian Coscoroba Swans during Molt
}

Cecilia Pérez Calabuig,,$^{1,2}$ Miguel Ferrer, ${ }^{1}$ and Roberto Muriel ${ }^{1}{ }^{1}$ Department of Ethology and Biodiversity Conservation, Estación Biológica de Doñana, CSIC, Avda. Americo Vespucio s/n, 41092, Sevilla, Spain; ${ }^{2}$ Corresponding author (email: cecicalabuig@ebd.csic.es)

ABSTRACT: The Coscoroba Swan (Coscoroba coscoroba) is an unusual member of the Anatidae found in South America, from the Falkland Islands and Tierra del Fuego through Chile and Argentina, Uruguay, and Paraguay as far north as Mato Grosso do Sul in Brazil. The species is not threatened globally, but some local populations have declined and the status of others is unknown. The objective of this study was to quantify the plasma chemistry of a wild population of Coscoroba Swans in southern Brazil during their molting period. We captured 12 chicks, 14 juveniles, and 31 mature birds. The following blood parameters were measured: glucose, cholesterol, triglycerides, HDL cholesterol, uric acid, creatin-kinase, aspartate amino transferase, alanine-aminotransferase, alkaline phosphatase, amylase, and pancreatic amylase. Significant differences between males and females were not observed for any of the parameters, and only the levels of alkaline phosphatase differed significantly among age groups.

Key words: Age-related differences, blood chemistry, Coscoroba Swan, free-living, molting period, sex-related differences.

The Coscoroba Swan (Coscoroba coscoroba) is a poorly known swan endemic to South America. In Chile, the species is under threat of extirpation (Glade, 1993). In Brazil, this swan is not on the list of threatened species, but is designated as an "insufficiently known" species and is probably in danger of extirpation (Nascimento et al., 2001). The species is sexually monomorphic, the plumage is white except for black tips on the outer six primaries, and the bill, legs, and feet are red. The greatest threat to the species is the loss of temperate marsh habitats (Silva-García and Brewer, 2007).

Collecting biochemical data from the blood of wild animals is difficult because multiple steps have to be taken. The challenge is greater with threatened or endangered species due to the limited number of individuals and to the height- ened consequences of the risks involved in capture and sampling of blood from these animals. These data may be of limited use because studies have not evaluated the effects of confounding factors such as physiologic state, age, sex, nutritional condition, circadian rhythm, season, and method of storing plasma (e.g., Mori and George, 1978; Driver, 1981; Ferrer, 1992; Dabbert and Powell, 1993).

To our knowledge, there are no published accounts of biochemical results from sampling the blood of free-ranging, wild Coscoroba Swans. The aim of this study was to quantify some key parameters of the blood chemistry of the principal population in Brazil. The data provide reference values for the normal physiologic parameters for both sexes and a range of ages.

We captured 57 swans including 12 chicks (four males, four females, and four of unknown sex), 14 juvenile birds (six females and eight males), and 31 mature swans (14 females and 17 males). All birds were captured outside the boundary of the “Estação Ecoló gica do Taim” Reserve (32u339S, 52u329W) in the southern coastal plain of the State of Rio Grande do Sul, Brazil. The juveniles and mature swans were captured in 2007 during the molting period (August-January) when they were not able to fly; the chicks were captured in December-January from clutches of four families. The birds were captured, by hand, by researchers in boats (Nascimento et al., 2001); birds were placed in a dark bag until they were sampled. The entire sampling process took about 15 min.

Birds were weighed and the maximum amount (safe limit) of blood extracted was $1 \%$ of their body mass (Lumeij, 1997). To minimize the effects of circadian rhythms, blood samples were collected between 9:00 AM and 4:00 PM (GMT-3) (Ferrer, 
1992); the needle gauge size chosen was just smaller than the radial vein diameter. For biochemistry, blood samples were placed in tubes containing heparin-lithium, kept cool (4 C) for a maximum of $5 \mathrm{hr}$, and centrifuged at 15,000 $3 \mathrm{G}$ for $10 \mathrm{~min}$. For gender identification, samples selected for analysis were not degraded (no hemolysis or lipemia). Samples were stored in VacutainerH tubes with EDTA (BD Bioscience, Franklin Lakes, New Jersey, USA) and kept cool on ice until processed.

Biochemical analyses were performed using a portable autoanalyser (Reflotron II; Boehringer Mannheim GembH, Mannheim, Germany) with the reagents recommended by Roche Diagnostics (Indianapolis, Indiana, USA) at $30 \mathrm{C}$. Blood parameters (abbreviations and methods in parentheses) quantified were: glucose (GLU; hexocinase method); cholesterol (CHOL; CHOD-PAP method); triglycerides (TRI; GPO-PAP method); HDL cholesterol (HDL-CHOL; HDL-cholesterin plus homogenic); uric acid (UR AC; urease and catalase method); creatine kinase (CK; creatine kinase liquid method); aspartate aminotransferase (AST; IFCC method); alanine-aminotransferase (ALT; IFCC method); alkaline phosphatase (ALP; IFCC liquid method); amylase (AMY; aamylase liquid method ); and pancreatic amylase (a-AMY; pancreatic a-amylase liquid method).

The age of each bird was determined by plumage characteristics (Johnsgard, 1978). Birds were classified as 0 yr old (chicks between eight and 21 days old), 1 yr old (juvenile), or more than 2 yr old (mature). The sex of mature birds was determined using the genital identification described by Proctor and Lynch (1993). Gender of juvenile birds was determined using DNA analysis at the Biotechnology Center, Federal University of Pelotas, Pelotas, Brazil. DNA extraction was performed according to Lahiri and Nurnberger (1991). After the extraction of DNA, we used the method described by $\mathrm{He}$ et al.
(2005) for the Black Swan (Cygnus atratus).

In order to compare mean concentrations of blood constituents among age groups and between the sexes, we used a two-way factorial analysis of variance (ANOVA), with age and sex as fixed factors and the chemical parameters as dependent variables, in a simple block design. The significance of the differences among groups was evaluated using the Wilks test. To compare mean concentrations of blood parameters between sexes, we used a oneway ANOVA and restricted the analysis to mature birds. To assess the normality and homoscedasticity of the data, we used the Lilliefors and Levene tests, respectively, and values were $\log _{10}$-transformed when appropriate. Creatine kinase and a-AMY were excluded from the analyses of mature birds because of small sample sizes. Statistical analyses were performed using Statistica 6.0 (StatSoft Inc., Tulsa, Oklahoma, USA), and differences were considered statistically significant when $P>0.05$.

This is the first study of the blood chemistry of wild Coscoroba Swans; therefore, results with more than six specimens for each sex (mature birds) were compared with other species of Anatidae in order to be of value in the clinical diagnoses of this species. Alkaline phosphatase, GLU, CHOL, and TRI levels were similar in relation to other anatids, whereas values of UR AC, AST, ALT, and AMY differed.

None of the animals suffered from any apparent disease, were visibly undernourished, or had other obvious physical problems. Body masses (mean6SD) were: chicks, 1,319.26272.6 g; juveniles, 3,562.36636.9 g; and mature individuals, 3,852.36517.1 g. Mature males and females did not differ significantly in any of the biochemical blood parameters evaluated (Table 1), nor was there a significant ( $P$ - 0.05) interaction between sex and age.

Only the concentrations of ALP differed significantly (df52,51; F597.7; P $>0.01$ ) 
TABLE 1. Blood chemistry of mature, wild Coscoroba Swans (Coscoroba coscoroba) captured during molt in southern Brazil.

\begin{tabular}{|c|c|c|c|c|c|c|c|c|}
\hline \multirow[b]{2}{*}{ ASSAY $^{\mathrm{a}}$} & \multicolumn{4}{|c|}{ Male } & \multicolumn{4}{|c|}{ Female } \\
\hline & $\mathrm{n}$ & Mean & SD & Range & $\mathrm{n}$ & Mean & SD & Range \\
\hline Weight (g) & 17 & $4,007.1$ & 406.6 & $3,200-4,700$ & 14 & 3,653.6 & 566.5 & $2,900-4,350$ \\
\hline GLU (mmol/l) & 12 & 5.3 & 4.1 & $1.1-14.2$ & 7 & 7.5 & 3.5 & 2-10.3 \\
\hline CHOL (mmol/l) & 16 & 3.5 & 0.8 & $2.7-5.3$ & 11 & 3.3 & 0.9 & $2.6-5.6$ \\
\hline TRI (mmol/l) & 16 & 1.6 & 0.3 & $0.9-2.3$ & 11 & 1.6 & 0.7 & $0.8-3.5$ \\
\hline HDL-CHOL (mmol/l) & 12 & 1 & 0.5 & $0.4-1.7$ & 7 & 1.1 & 0.6 & $0.4-2.2$ \\
\hline UR AC (mmol/l) & 12 & 143.8 & 45 & $119-245.6$ & 6 & 146.8 & 29.8 & 119-196.3 \\
\hline $\mathrm{CK}(\mathrm{U} / \mathrm{l})^{\mathrm{b}}$ & 5 & $1,166.8$ & 521.9 & 496-1,952 & 3 & $1,144.7$ & 659.5 & $500-1,818$ \\
\hline AST (U/l) & 9 & 147.7 & 62.5 & $56-274$ & 6 & 123 & 36.9 & 88.1-178 \\
\hline ALT (U/l) & 11 & 13.5 & 10.5 & $3.8-36.8$ & 8 & 18 & 9 & 8.4-38.9 \\
\hline ALP (U/l) & 16 & 70 & 30.7 & 20-120 & 13 & 55.3 & 34.2 & 20-121 \\
\hline AMY (U/l) & 13 & $1,452.6$ & 692.5 & $510.6-2,920$ & 6 & $1,405.3$ & 571.4 & $732-225$ \\
\hline $\mathrm{a}-\mathrm{AMY}(\mathrm{U} / \mathrm{l})^{\mathrm{b}}$ & 8 & $1,642.9$ & 708.2 & $678-2,823$ & 3 & $1,122.7$ & 523.1 & $620-1,664$ \\
\hline
\end{tabular}

${ }^{\text {a }}$ See text for definition of assay abbreviations.

b Blood parameters that were excluded from the analyses and discussion.

among age groups, but not between sexes. The activity of ALP gradually diminishes as the animals age, and the levels of ALP for chicks differed significantly from those in juveniles $(P, 0.01)$ and mature individuals $(P>0.01$; Table 2$)$. Similar, age-related differences in ALP occur in other anatids (Gee et al., 1981; Olsen et al., 2002; Boettcher, 2004). The decrease in ALP activity with age is associated with a reduction in ossification rates, because ALP is involved in osteogenesis and is produced by bone-forming cells (osteoblasts; Bell and Freeman, 1971).

Glucose, CHOL, and TRI concentrations are related to the quantitative and qualitative composition of the diet (Polo, 1995). Cholesterol levels were similar to those found in captive Canada Goose (Branta canadensis), Greater White-fronted Goose (Anser albifrons), and Domestic Goose (Anser anser domesticus) (Polo, 1995; Gee et al., 1981; Carpenter et al., 2001). Triglyceride levels were within the normal range for most anatids (Gee et al., 1981; Perry et al., 1986) and other birds (Polo, 1995), and the three parameter levels were similar to those found in another wild neotropical swan, the Blacknecked Swan (Cygnus melanocoryphus; Polo, 1995; Boettcher, 2004).
The levels of UR AC were higher than levels reported in other species of anatids (Driver, 1981; Gee et al., 1981; Levengood et al., 2000; Dombrowski et al., 2003), probably because the diet of the wild swans was not rich in animal protein. Polo (1995) attributed the low UR AC concentrations found in Anseriformes to an herbivorous diet, but the swans in our study were not exclusively herbivorous. In captive and wild Mallards (Anas platyrhynchos), the levels of UR AC during, and following, molt were higher than levels before molt. In wild B. canadensis, UR AC levels varied depending on the phase of the annual cycle (Mori and George, 1978). Thus, it appears that, for specific physiologic reasons (e.g., higher demand for UR AC) during specific periods, birds have low levels of UR AC because the nutrients available in the diet at the time of molting, when the birds cannot fly, differ from other times of the year.

Levels of AST were similar to, or higher, than those reported in birds that had myopathy (Wobeser and Howard, 1987). Yet, there are studies in which individuals did not show signs of capture myopathy, or other trauma, but had high AST levels. These include the Wood Duck (Aix sponsa), B. canadensis, and C. 
TABle 2. Descriptive one-way analysis of variance for significant differences in alkaline phosphatase (I/l) blood levels among age classes for Coscoroba Swan captured during molt in southern Brazil.

\begin{tabular}{lccccc}
\hline \multicolumn{1}{c}{ Age } & $\mathrm{n}$ & Mean $^{\mathrm{a}}$ & $\mathrm{SD}$ & $\mathrm{SE}$ & \multicolumn{1}{c}{ Range } \\
\hline Total & 54 & 280.5 & 482.2 & 65.6 & $20.0-2,110.0$ \\
Chicks & 11 & $1,077.8 \mathrm{~A}$ & 585.6 & 176.6 & $345.0-2,110.0$ \\
Juveniles & 14 & $103.9 \mathrm{~B}$ & 72.6 & 19.4 & $31.5-326.0$ \\
Matures & 29 & $63.4 \mathrm{AB}$ & 32.6 & 6 & $20.0-121.0$ \\
\hline
\end{tabular}

${ }^{\mathrm{a}}$ Means followed by different letters are significantly different $(P>0.01)$.

melanocoryphus in captivity (Polo, 1995); wild A. platyrhynchos (Dabbert and Powell, 1993); wild Canvasback (Aythya valisineria) (Perry et al., 1986); and A. a. domesticus in captivity (Gee et al., 1981). Aspartate aminotransferase also tended to be higher in mature than in younger birds (Gee et al., 1981; Olsen et al., 2002). Blood levels of AST can be affected by a variety of factors such as season, bird physiology, nutritional state, and method of capture (Bell and Freeman, 1971; Driver, 1981; Dabbert and Powell, 1993). In our study, Coscoroba Swans were captured and handled in a manner that differed from other studies (see methods), a manner that might have increased stress on the animals and could have resulted in higher AST levels than studies using conventional capture methods.

Levels of ALT were lower than typical levels reported in anatids (e.g., Driver, 1981; Gee et al., 1981; Perry et al., 1986; Polo, 1995; Boettcher, 2004), but similar to those found in American Black Duck (Anas rubripes), A. platyrhynchos, and A. valisineria in captivity (Franson, 1982; Olayemi et al., 2002). Ho et al. (2002) found that ALT activity was higher during the growing period in ducks. In contrast, juvenile Coscoroba Swans tended to have levels of ALT that were lower than those in adult birds.

Levels of AMY were higher than those reported in other anatids such as B. canadensis, Hawaiian Goose (Branta sandvicensis), $A$. albifrons, and A. a. domesticus (Gee et al., 1981), but lower than levels observed in A. platyrhynchos (Levengood et al., 2000); in addition, levels tended to be higher in mature than in younger birds.

In conclusion, we report normal values of plasma chemistry and their differences in relation to sex and age. Whereas some of the metabolites showed concentrations within ranges described for other anatids, others differed as a result of variation in diet composition, biologic cycle, molt stage, or capture methods. Despite a small sample size for some parameters, our results exhibited a general homogeneity between genders and age classes for most of the biochemical parameters tested in Coscoroba Swans. The only noticeably higher values were detected for ALP in chicks, as ALP is an enzyme directly related to the maximum osteoblastic activity during structural development in the first months of life, followed by a subsequent reduction with age. These results may be useful as reference values in future biologic research and veterinary diagnosis in this species.

We thank Heden Moreira, Bernardo Vaz, and Janaina Camacho of the CenBiot, UFPel, Brazil for performing the DNA identifications of nonmature Coscoroba Swans.

\section{LITERATURE CITED}

Boettcher, A. A. 2004. Valores bioquímicos sanguíneos del cisne de cuello negro (Cygnus melanocoryphus, Molina, 1782), en una población silvestre de Valdivia, Chile. BS Thesis, Universidad Austral de Chile, Valdivia, Chile, 62 pp.

Bell, D. J., and B. M. Freeman. 1971. Physiology and biochemistry of the domestic fowl. Physiology \& biochemistry of the domestic fowl 3: 1153-1488.

Carpenter, J., T. Mashima, And D. Rupiper. 2001. 
Exotic animal formulary, 2nd Edition. W. B. Saunders Company, Philadelphia, Pennsylvania, $423 \mathrm{pp}$.

Dabbert, C., and K. Powell. 1993. Serum enzymes as indicators of capture myopathy in mallards (Anas platyrhynchos). Journal of Wildlife Diseases 29: 304-309.

Dombrowski, P., J-C. Bourgeois, R. Couture, And C. LinARD. 2003. Estimation of carcass fat and protein in northern pintails (Anas acuta) during spring migration. Journal of Wildlife Diseases 39: 620-626.

Driver, E. A. 1981. Hematological and blood chemical values of mallard, Anas p. platyrhynchos, drakes before, during and right after remige molt. Journal of Wildlife Diseases 17: 413-421.

Ferrer, M. 1992. Blood chemistry studies in birds: Some applications to ecological problems. Comparative Biochemistry and Physiology 1: 10311044.

Franson, J. C. 1982. Enzyme activities in plasma, liver, and kidney of black ducks and mallards. Journal of Wildlife Diseases 18: 481-485.

Gee, G. F., J. W. Carpenter, and G. L. Hensler. 1981. Species differences in haematological values of captive cranes, geese, raptors and quail. Journal of Wildlife Management 45: 463483.

Glade, A. A. 1993. Libro rojo de los vertebrados terrestres de Chile. Corporación Nacional Forestal (CONAF), Santiago de Chile, Chile, 68 pp.

He, P-J., J-Q. Yu, And S-G. Fang. 2005. Sex identification of the black swan (Cygnus atratus) using the locus-specific PCR and implications for its reproduction. Reproduction in Domestic Animals 40: 196-198.

Ho, W., Y. Shien, B. Chen, and S. Lai. 2002. Comparison of serum chemistry values in inbred duck (L103) white Tsaiya and its parent stock of brown Tsaiya duck. Taiwan Veterinary Journal 28: 260-265.

Johnsgard, P. 1978. Ducks, geese, and swans of the world. University of Nebraska Press, Lincoln, Nebraska, 404 pp.

Lahiri, D. K., And J. I. Nurnberger. 1991. A rapid nonenzymatic method for the preparation of HMW DNA from blood for RFLP studies. Nucleic Acids Research 19: 5444.

Levengood, J. M., G. C. Sanderson, W. L. Anderson, G. L. Foley, P. W. Brown, and J. W. SEets. 2000. Influence of diet on the hematology and serum biochemistry of zinc- intoxicated mallards. Journal of Wildlife Diseases 36: 111-123.

Lumeis, J. 1997. Avian clinical biochemistry. In Biochemistry of domestic animals, 5th Edition, J. J. Kaneko, J. W. Harvey and M. L. Buss (eds.). Harcourt Brace and Company, Orlando, Florida, pp. 857-883.

Mori, J. G., And J. C. George. 1978. Seasonal changes in serum levels of certain metabolites, uric acid and calcium in the migratory Canada goose (Branta canadensis interior). Comparative Biochemistry and Physiology B 59: 263-269.

Nascimento, J. L. X., J. M. Flores, B. S. Ataguile, M. Koch, S. Barbosa, and P. J. Parreira Dos SANTOS. 2001. Biological aspects of the blacknecked swan (Cygnus melancoryphus) and coscoroba swan (Coscoroba coscoroba) in Rio Grande do Sul state, Brazil. Melopsittacus 4: 3138.

Olayemi, F. O., R. O. A. Arowolo, A. B. Saba, and S. A. Famakinde. 2002. Effect of sex on the blood profiles of the Nigerian local duck. Bulletin of Animal Health and Production in Africa 50: 6771.

Olsen, G., D. Rininger, M. Ets, and W. Sladen. 2002. Baseline haematology and clinical chemistry results from captive-raised trumpeter swans. Waterbirds 25 (Special Publication 1): 375-379.

Perry, M., H. Obrecht, B. Williams, and W. Kuenzel. 1986. Blood chemistry and hematocrit of captive and wild canvasbacks. Journal of Wildlife Management 50: 435-441.

Polo, F. J. 1995. Estudio bioquimico y enzimatico del plasma de aves en cautividad. PhD Thesis. Universidad de Barcelona, Barcelona, Spain, 381 pp.

Proctor, N. S., AND J. P. Lynch. 1993. Manual of ornithology: Avian structure and function. Yale University Press, New Haven, Connecticut, 340 pp.

Silva-Garcia, C. M., and G. L. Brewer. 2007. Breeding behavior of the coscoroba swan (Coscoroba coscoroba) in El Yali wetland, central Chile. Ornitología Neotropical 18: 573585.

Wobeser, G., AND J. Howard. 1987. Mortality of waterfowl on a hypersaline wetland as a result of salt encrustation. Journal of Wildlife Diseases 23: $127-134$.

Submitted for publication 19 March 2009. 